\title{
Late Diagnosis of HIV Infection in Children: Prevalence and Outcome
}

\author{
Aymar Pierre Gildas 0ko1,2*, Antoinette Géraldine Olandzobo3 ${ }^{3}$ Gaston Ekouya-Bowassa1,2, \\ Mamadou Ildevert Cyriaque Ndjobo', Lucie Ollandzobo',2, Nelly Pandzou-Guembo', \\ Letitia Lombet ${ }^{1}$, Jeysse Pierre Yoleine Poathy ${ }^{1}$, Steve Vassili Missambou-Mandilou ${ }^{1}$, \\ Aurore Mbika-Cardorelle ${ }^{1,2}$, Georges Marius Moyen ${ }^{1,2}$
}

\author{
${ }^{1}$ Department of Pediatrics, Teaching Hospital Center (THC) of Brazzaville, Brazzaville, Congo \\ ${ }^{2}$ Faculty of Health Sciences, Marien Ngouabi University of Brazzaville, Brazzaville, Congo \\ ${ }^{3}$ Hospital Center of Loandjili, Pointe-Noire, Congo \\ Email: *aymaroko@yahoo.fr
}

\begin{abstract}
How to cite this paper: Oko, A.P.G., Olandzobo, A.G., Ekouya-Bowassa, G., Ndjobo, M.I.C., Ollandzobo, L., Pandzou-Guembo, N., Lombet, L., Poathy, J.P.Y., Missambou-Mandilou, S.V., Mbika-Cardorelle, A. and Moyen, G.M. (2017) Late Diagnosis of HIV Infection in Children: Prevalence and Outcome. Open Journal of Pediatrics, 7, 331-344. https://doi.org/10.4236/ojped.2017.74038
\end{abstract}

Received: November 12, 2017 Accepted: December 12, 2017 Published: December 15, 2017

Copyright $\odot 2017$ by authors and Scientific Research Publishing Inc. This work is licensed under the Creative Commons Attribution International License (CC BY 4.0).

http://creativecommons.org/licenses/by/4.0/

\begin{abstract}
Background: Late diagnosis of HIV infection is an important cause of death in children. Objectives: To determine the prevalence of late diagnosed HIV infection in children, describe the socio-demographic characteristics and to analyze outcome of these children. Methods: From January 2015 to October 2016, we carried out a prospective analytical study in the pediatric departments of University Teaching Hospital of the Brazzaville. Late diagnosed HIV children were selected for this work. Data analysis was performed in univariate and multivariate with Epi Info 7.2.1. Results: Of the 6058 hospitalized children, 103 (1.7\%) were selected, $57.3 \%$ were boys; the median age was 21.9 months (IQR, 17.8 - 76.7 months). Children of low socio-economic status accounted for $68.0 \%$, those motherless: $43.7 \%$. None of the children were tested for HIV before hospitalization. Mothers had a low education level in $60.2 \%$ of cases and were unaware of prevention of mother-to-child transmission (PMTCT): $60.3 \%$. Children mostly showed signs of stages $4(49.5 \%)$, and $3(31.1 \%)$ of HIV infection, immunodeficiency was severe for $68.0 \%$ of children. Children discharged from the hospital accounted for $62.1 \%$ of which $15.53 \%$ against medical advice. The case fatality rate was $37.9 \%$. The risk factors for death in univariate analysis were: age $<12$ months $(\mathrm{OR}=8.66)$, maternal death $(\mathrm{OR}=$ 17.93), severe malnutrition $(\mathrm{OR}=66.07)$, clinical stages $4(\mathrm{OR}=66.07)$ and severe immunodeficiency $(\mathrm{OR}=17.37)$. The main pathologies responsible for death were respiratory infections (38.5\%) and diarrheal diseases (30.8\%). Conclusion: Improvement of PMTCT program effectiveness, universal access to early detection and antiretroviral therapy for infants are needed to reduce the number of late diagnosed HIV-children and therefore HIV-related morbidity and
\end{abstract}


mortality.

\section{Keywords}

Late Diagnosis, HIV Infection, Prevalence, Mortality, Child, Brazzaville

\section{Introduction}

Human Immunodeficiency Virus (HIV) infection described for the first time in children in the $80 \mathrm{~s} \mathrm{[1]}$, has had different epidemiological evolution depending on the regions and countries. In high income countries, after a critical period, the epidemiological situation has changed drastically: mother-to-child transmission of HIV infection has almost been eliminated through an effective prevention policy, morbidity and mortality have been significantly reduced by the early and wide use of high-activity antiretroviral therapy (HAART) in children [2] [3]. In low and middle income countries, especially those located in sub-Saharan Africa, despite the successes in the response to HIV infection, it still contributes significantly to the childhood morbidity and mortality [4] [5]; In 2016, UNAIDS estimated that 2.1 million children under 15 years were living with HIV, among whom 160,000 new cases and nearly $90 \%$ of these children were in sub-Saharan Africa. Of the estimated 1.0 million people who died of AIDS-related illnesses in 2016, 120,000 of them were children under 15 years of age and the vast majority of these deaths occur in sub-Saharan Africa [5]. One of the main causes of HIV-related morbidity and mortality still high in Africa is late diagnosis and consequently late initiation of antiretroviral therapy (ART) [6]. Indeed several studies highlight the survival benefit of early initiation of antiretroviral therapy for HIV-infected infants especially when ART was initiated before the clinical signs and symptoms of HIV infection [6] [7] [8]. And based on these data, the WHO has changed its treatment recommendations, calling for treatment of all infected infants under 24 months of age, irrespective of clinical stage and CD4 count; To improve early access to pediatric antiretroviral therapy, WHO recommends that countries with high incidence should ensure scaling up of program services prevention of mother-to-child transmission (PMTCT) of HIV infection and routine early detection infant [9]. Despite these recommendations, the number of HIV-children diagnosed late in hospital remains high in Africa [10] [11]. The proportion of late diagnosed HIV-infected children is also a good indicator of the effectiveness of HIV-related services in a country, especially prevention and screening. In Congo, child data are rare, in 2016, UNAIDS estimated that 6000 children living with HIV, 1100 newly infected children, and HIV infection is one of the main causes of death in children with nearly 1000 deaths [12] [13]. Furthermore, the prevalence of HIV infection remains high among pregnant women, the knowledge of the PMTCT program by them is poor and coverage of PMTCT services is low [12] [14]. Additionally, early detection was only performed in 3\% of PMTCT in- 
fants and for the moment early detection is not yet routinely offered to all infants, as currently recommended by WHO [9] [15]. All these data indicate potential deterioration of the epidemiological situation of HIV infection in children, including an increase in the number of late diagnosed HIV-infected children. In this work, we sought in era of the PMTCT, routine early diagnosis in infants and HAART, to determine the prevalence of late diagnosed HIV infection in children, to describe socio-demographic characteristics and to analyze outcome of late diagnosed HIV-children.

\section{Methodology}

\subsection{Setting}

The study was carried out in the pediatric departments of the University Teaching Hospital (UTH) of Brazzaville. Brazzaville is the capital of the Republic of Congo and the UTH, the national referral hospital. The population of Brazzaville was estimated at $1,373,382$ at the last national census (2009), HIV prevalence is $3.1 \%$ in adults and 6000 children live with HIV [12]. PMTCT activities started in 2003 and are being carried out to date as a project [16]. The coverage of early detection of PMTCT infants is only $3 \%$. Pediatric care of HIV infection has been free since 2008 , but only $23 \%$ of infected children are supported [12] [17].

\subsection{Study Design and Patients}

We carried out a prospective analytical study between January 2015 and July 2016. All children aged from 1 month to 17 years hospitalized in the pediatric wards of the UTH of Brazzaville and presenting suggestive manifestations of the HIV infection according to the clinical definition of WHO cases [18], have undergone a HIV rapid antibody diagnostic test. In case of positive test, a polymerase chain reaction (PCR)-DNA test was performed in children under 18 months of age or a confirmatory second rapid antibody diagnostic test in those aged 18 months and over. Pre- and post-test counseling was performed in all screened children. Children meeting the criteria for late diagnosed HIV infection as defined for the study [19] were included systematically and consecutively.

\subsection{Data Collection}

We recorded all data on a standardized and structured form. The data included two types of variables: variables relating to children and those for parents/caregivers. For children, we recorded: age, gender, pathological history suggestive of HIV infection, nutritional status as assessed by WHO standards [20], clinical stage of disease and immune status according to WHO clinical and immunological classifications [21], the cause of hospitalization and evolution. For mothers/caregivers: age, vital status, educational level, socio-economic status, HIV knowledge, knowledge of PMTCT, health status.

The sources of information were the caregiver of the child, the child himself 
when he was able to express, the attending physician and medical records.

\subsection{Definitions}

HIV status: HIV infection was defined as a positive HIV rapid antibody diagnostic and PCR tests results for Children under 18 months and as two positive HIV rapid antibody diagnosis tests results for those aged 18 months and over.

The diagnosis of HIV infection was considered late when it was made after the onset of the signs of the disease in children aged 5 and under, and in those over 5 when the signs of the disease corresponded to clinical stage 3 or 4 or when advanced or severe immunodeficiency [20] [21].

Nutritional status as assessed by WHO standards [20]: we assessed the children's nutritional status using $z$-scores of weight-for-length (or weight-for-height). Children with values below $-2 z$-scores (below $-3 z$-scores) of the reference population were considered moderately malnourished (severely malnourished), those with values between -2 and $2 \mathrm{z}$-scores normal, and the values above $2 \mathrm{z}$-scores (above $3 \mathrm{z}$-scores) indicated overweigh (obesity).

Socio-economic status (SES) was assessed using the National Congolese Center for Statistics and Economic Studies (CNSEE) classification [22], the socio-economic level of family was considered low when family expenses for meals were estimated less than 523 FCFA (African Financial Community Franc. 1 Dollar = 550 FCFA) per person per day, middle between 523 and 1685 FCFA and high between 1685 and 5055 FCFA.

\subsection{Statistical Analysis}

The data was processed and analyzed with Epi info 7.2.1 software. Quantitative variables were expressed in median and interquartile range (IQR) and qualitative variables in percent. The numbers of each variable were also specified. The percentages were compared with the independence Chi-2 test or the Fischer test (when at least one of the theoretical numbers was less than 5) and the odds ratio (OR). In the multivariate logistic regression model, we included only variables significantly associated with death from the univariate analysis $(\mathrm{p} \leq 0.20)$. The significance level was set at $5 \%$ and the $95 \%$ confidence interval (CI).

\subsection{Ethical Considerations}

We obtained informed consent from parents/caregivers for interviews. The study was conducted in compliance with the Helsinki Declaration [23]. The study was approved by the National Ethics Committee.

\section{Results}

\subsection{Description of the Population}

From January 2015 to July 2016, 6058 children were hospitalized to UTH, among them 103 (1.7\%) HIV-infected children, all of whom meet the criteria for late 


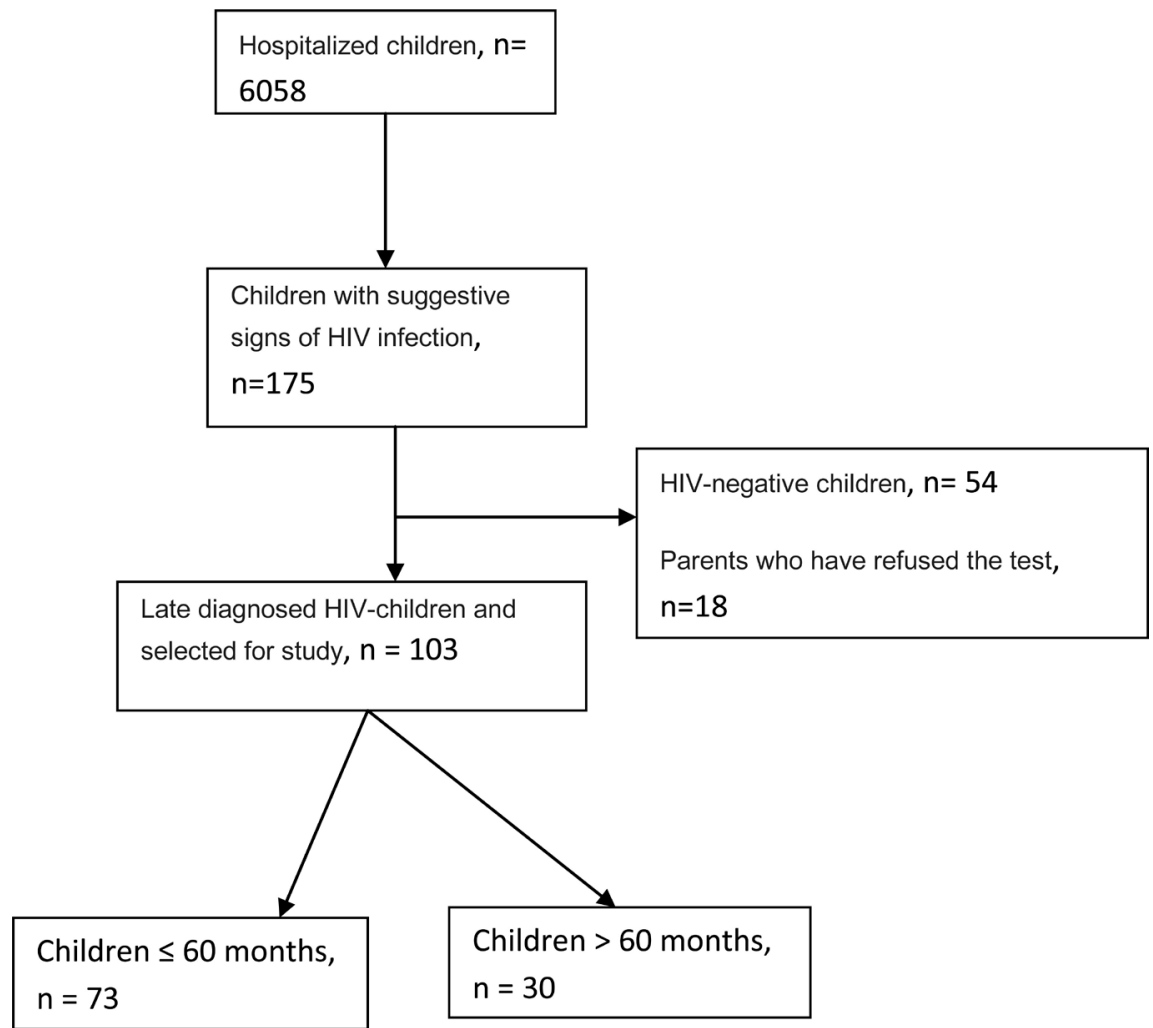

Figure 1. Patient selection flow diagram.

diagnosed HIV infection and were included in our study (the patient selection flow diagram is shown in Figure 1). There were 59 boys (57.3\%) and the sex ratio was 1.3. median age was 21.9 months (IQR, 17.8 - 76.7 months). Forty-five (43.7\%) children were orphaned by mother. The reasons of maternal deaths have not been formally identified; however, close relatives have often described HIV related reasons.

The socio-demographic, clinical and evolutionary characteristics of the population are detailed in Table 1.

\subsection{Knowledge and Practices}

HIV knowledge assessed in all caregivers was considered good in 30 (29.1\%) of them, acceptable in 50 (48.6\%) and poor in 23 (22.3\%). The existence of the PMTCT program was known by 23 (39.7\%) of the 58 living mothers. Twenty mothers (34.5\%)/58 reported having been tested for HIV during pregnancy; for 10 mothers the test result was negative in the first trimester, 3 mothers did not know the test result and for the 7 others the test result was positive. 5 out of 7 HIV-positive mothers had initiated antiretroviral therapy, which was subsequently discontinued for a variety of reasons (denial of the disease, fear of stigma and discrimination, fear that the spouse discovers her status and stock-outs of antiretroviral), and 2 others did not received antiretroviral therapy.

None of the children were tested for HIV before hospitalization, even those whose mothers were diagnosed with HIV during pregnancy. 
Table 1. Socio-demographic and clinical characteristics of HIV children and parents.

\begin{tabular}{|c|c|c|}
\hline Characteristics & $\mathrm{n}(\%)$ & Cumulative frequency (\%) \\
\hline \multicolumn{3}{|l|}{ Age group (month) } \\
\hline$[1-11]$ & $38(36.9)$ & 36.9 \\
\hline [12 - 23] & $15(14.6)$ & 51.5 \\
\hline$[24-60]$ & $20(19.4)$ & 70.9 \\
\hline$[61-120]$ & $16(15.5)$ & 86.4 \\
\hline$>120$ & $14(13.6)$ & 100.0 \\
\hline \multicolumn{3}{|l|}{ Gender } \\
\hline Male & $59(57.3)$ & 57.3 \\
\hline Female & $44(42.7)$ & 100.0 \\
\hline \multicolumn{3}{|l|}{ Vital status of parents } \\
\hline Mother deceased & $45(43.7)$ & \\
\hline Father deceased & $34(33.0)$ & \\
\hline Both deceased parents & $25(24.3)$ & \\
\hline \multicolumn{3}{|l|}{ School level of the mother } \\
\hline Never schooled & $29(28.2)$ & 28.2 \\
\hline Primary & $33(32.0)$ & 60.2 \\
\hline Secondary & $21(20.4)$ & 80.6 \\
\hline University & $8(7.8)$ & 88.4 \\
\hline Unspecified & $12(11.6)$ & 100.0 \\
\hline \multicolumn{3}{|l|}{ Socio-economic status } \\
\hline High & $7(6.8)$ & 6.8 \\
\hline Middle & $26(25.2)$ & 32.0 \\
\hline Low & $70(68.0)$ & 100.0 \\
\hline \multicolumn{3}{|l|}{ Nutritional status } \\
\hline Normal & $7(6.8)$ & 2.9 \\
\hline Moderate malnutrition & $45(43.7)$ & 32.0 \\
\hline Severe malnutrition & $51(49.5)$ & 100.0 \\
\hline \multicolumn{3}{|l|}{ Clinical stage (WHO) } \\
\hline Stage 1 & - & \\
\hline Stage 2 & $20(19.4)$ & 19.4 \\
\hline Stage 3 & $32(31.1)$ & 68.9 \\
\hline Stage 4 & $51(49.5)$ & 100.0 \\
\hline \multicolumn{3}{|l|}{ Immunodeficiency (WHO) } \\
\hline None or not significant & - & \\
\hline Mild & $2(1.9)$ & 1.9 \\
\hline Advanced & $31(30.1)$ & 32.0 \\
\hline Severe & $70(68.0)$ & 100.0 \\
\hline
\end{tabular}




\subsection{Causes of Hospitalization}

The main causes of hospitalization were bronchopulmonary infections, which accounted for $51.5 \%$ of cases (including pulmonary tuberculosis) and diarrheal diseases (39.8\%) (Figure 2).

\subsection{Outcome}

Among the 103 children identified, 48 (46.6\%) were discharged with ART, sixteen children (15.53\%) went out against medical advice. for 39 children (37.9\%), the evolution was towards a death. The median duration of hospital stay was 9 days (IQR, 6 - 14 days).

The risk factors for death was identified only in univariate analysis, the multivariate analysis showed no risk factors independently associated with death (Table 2).

The pathologies responsible for death were: bronchopulmonary infections $\mathrm{n}=$ $15(38.5 \%)$, diarrheal diseases $n=12(30.8 \%)$, pulmonary tuberculosis $n=4$, malaria $\mathrm{n}=3$, meningitis and encephalitis 2 cases each and anemia 1 case.

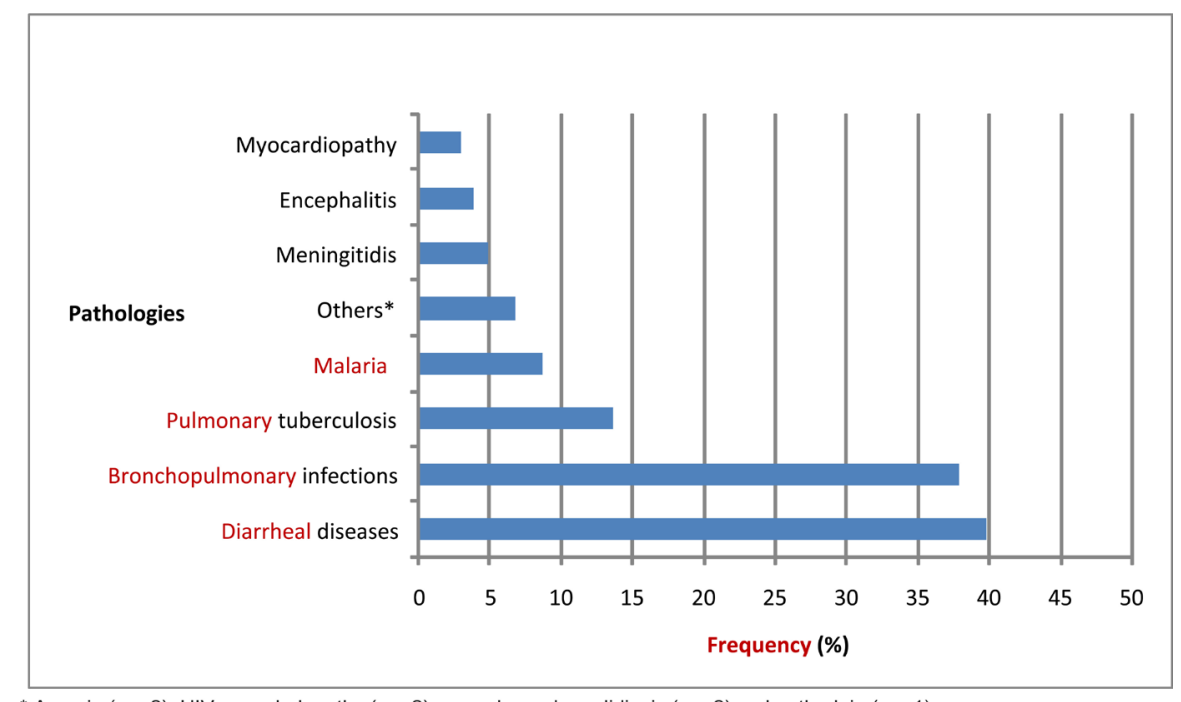

*Anemia $(n=2)$, HIV encephalopathy $(n=2)$, oesophageal candidiasis $(n=2)$, polyarthralgia $(n=1)$.

Figure 2. Causes of hospitalization of HIV children at University Teaching Hospital of Brazzaville during the study.

Table 2. Risk factors of death.

\begin{tabular}{cccccc}
\hline \multirow{2}{*}{ Variables } & Deceased & \multicolumn{2}{c}{ Univariate analysis } & \multicolumn{2}{c}{ Mulivariate analysis } \\
\cline { 3 - 6 } & $\mathrm{N}(\%)$ & OR [CI] & $\mathrm{p}$ & Adjusted OR [CI] & $\mathrm{p}$ \\
\hline Age $<12$ months & $26(68.4)$ & $8.66[3.47-21.63]$ & 0.000001 & $0.36[0.03-3.34]$ & 0.37 \\
Maternal death & $32(71.1)$ & $17.93[6.46-49.71]$ & 0.0000 & $1.20[0.05-24.47]$ & 0.90 \\
Clinical stage 4 & $37(72.6)$ & $66.07[14.14-308.62]$ & 0.0000 & - & 0.95 \\
Severe malnutrition & $37(72.6)$ & $66.07[14.14-308.62]$ & 0.0000 & - & 0.96 \\
Severe immunodeficiency & $37(52.9)$ & $17.37[3.85-78.27]$ & 0.000004 & $0.0[0.00-1.0 \mathrm{E} 12]$ & 0.90 \\
\hline OR = odds ratio; CI = confidence interval. & & & &
\end{tabular}




\section{Discussion}

This work allowed us to determine the number of late diagnosed HIV-infected children in the UTH of Brazzaville and to analyze mortality. The prevalence of $1.7 \%$ noted in this work is lower than those reported by MOYEN (3\%) and MBIKA (2.5\%) respectively in 1993 and 1998 [24] [25], but close to that reported by M'PEMBA (1.9\%) in 2003 and Dicko-Traoré (1.8\%) in Mali in 2013 [11] [26]. The first three studies were also conducted at the UTH of Brazzaville, but unlike the present study, they were conducted before the implementation of the PMTCT program and the introduction of free ART in the Congo [16] [17]. Notwithstanding methodological differences, these hospital data show that the prevalence of HIV infection discovered late during hospitalization has remained relatively stable over the past decade, despite the various control measures implemented in the Congo. In addition, the prevalence observed in this work is likely underestimated because only children with suggestive symptomatology of HIV infection according to WHO criteria [18] were tested; these WHO criteria do not identify all infected children because of their low sensitivity and specificity [27] [28] [29]. Routine HIV testing of all hospitalized children with unknown HIV status, as recommended by WHO [9] [15], would allow to have the actual prevalence. Kankassa found a HIV prevalence (29.2\%) significantly higher than that observed in this study, after routine screening of almost all (87.4\%) children hospitalized at UTH of Lusaka [29].

The often late and advanced diagnosis of HIV infection in children is a reality in many low and middle income countries [11] [30] [31] [32], the main reasons for the low impact of control measures on the prevalence of late diagnosed HIV infection are the insufficient coverage of PMTCT services, the lack of an effective early HIV testing policy for infants (PMTCT beneficiary or not), denial of the disease, fear of discrimination and stigma of people living with HIV. In our study more than $60 \%$ of the mothers were unaware of the PMTCT program, only $34.5 \%$ were tested for HIV during pregnancy and those who knew their HIV-positive status were either in denial or fear of stigma and discrimination, to the point of refusing treatment. Kambourou et al. still in the Congo had found such a large proportion (53.2\%) of mothers who did not know about the PMTCT program [14]. despite WHO recommendations on early and routine screening of infants, practices of child health professionals are not appropriate because none of the children in this study have been detected before. Other African countries, such as Congo, have difficulties in implementing and scaling up HIV services [33] [34] [35]. To remedy this situation, of course, all of these contributing factors must be addressed, but early diagnosis of HIV in infants must be a priority and full use of new technologies and service delivery strategies. Thus, HIV-related services can be combined with other child-care offerings: Counseling and early detection of HIV infection in infants can be routinely offered at birth, at vaccination sites, weighing, at the level of consultation and hospitalization services to increase the number of children detected early. The expansion HIV services in the commu- 
nity is also an effective way to reach populations, particularly those without access to the health system, as demonstrated by the SEARCH (Sustainable East Africa Research in Community Health) project [36]. To meet these challenges will no doubt require investment in key areas such as training and support for child health professionals, improvement of laboratory facilities and referral networks, and community mobilization.

HIV infection in this work was often early-onset, $36.9 \%$ of children less than 1 year old and the majority less than 2 years old at the time of diagnosis. The high incidence of early clinical form of HIV infection in children in Africa is a known fact [37] [38] and requires the implementation of an effective screening strategy to identify these infected infants prior disease progression. The antenatal and per-partum contamination associated with the very advanced state of infection in the mothers, as suggested by the high maternal mortality rate in our study, the multiple deficiencies in the mother and in the child are the main reasons for this high frequency [39] [40] [41].

The pathologies responsible for hospitalization and death were dominated by respiratory infections and diarrheal diseases, as already reported by other authors [11] [42] [43]. Most of these diseases are preventable by hygiene measures, vaccination and especially cotrimoxazole chemoprophylaxis.

The mortality rate observed in this study is particularly high, other authors consulted reported similar mortality rates [43] [44]. The severity of the clinical symptomatology following the late diagnosis explains this high mortality rate. The Children with HIV Early Antiretroviral Therapy (CHER) trial showed that initiation of antiretroviral therapy before the symptoms and signs of HIV infection reduced mortality by $75 \%$ [7], several others studies have also shown the benefit early initiation of ART in reducing mortality [6] [8] [45] [46]. In response, WHO now recommends initiating ART as soon as possible after the diagnosis of HIV infection in children and routinely in HIV-infected infants under 2 years of age [9].

The Congo has adopted these recommendations, but is still slow to ensure that these recommendations are scaled up.

The risk factors for death identified in univariate analysis in this work are identical to those reported by other authors [47] [48], most of whom are directly or indirectly related to the severity of the clinical symptomatology. With regard to maternal death, it increases the vulnerability of these children because of precarity, lack of love, and maternal attention and sometimes lack of care. No risk factors independently associated with death were found in the multivariate analysis. Caution is however needed when interpreting these results, since sample size was small and likely insufficient to detect significant differences among deceased group and survivals group.

\subsection{Limitations}

This work presents some limitations, the first concerns the site of the study, the fact that it was performed in a single hospital makes it difficult to extrapolate the 
results to the whole country, however, the UTH is the center where the majority of late diagnosed HIV-children are hospitalized. The second is related to the study population, it would have been interesting to compare children diagnosed late to those diagnosed early to better identify the causes behind the late diagnosis. Routine screening of all hospitalized children would have made it possible to have the actual prevalence. And the small size of our sample did not allow identify risk factors for death in multivariate analysis.

\subsection{Implications}

Despite its limitations, this study is the first on this subject since the implementation of PMTCT and setting up free healthcare for HIV in Congo and our findings draw the attention of health authorities and health professionals to the importance of late diagnosis of HIV infection in HIV-related morbidity and mortality in Brazzaville and probably in many cities in sub-Saharan Africa, to emphasize the value of early diagnosis and treatment of HIV infection in children for reducing mortality, and finally to describe the factors that contribute to late diagnosis.

\section{Conclusion}

Late diagnosed HIV infection remains common and causes heavy mortality in children in Brazzaville. Congo should build capacity in its PMTCT program, but also implement an effective strategy for routine early detection of HIV infection and treatment of infected children to reduce prevalence, improve diagnosis of infection HIV and therefore reduce HIV-related morbidity and mortality in children.

\section{Acknowledgements}

We thank all the staff of the Pediatric Department at UTH of Brazzaville for their enthusiastic collaboration and hard work on this project. We are indebted to children and caregivers who participated in the study.

\section{Competing Interests}

The authors declare that they have no competing interests.

\section{References}

[1] Cowan, M.J., Hellmann, D., Chudwin, D., Wara, D.W., Chang, R.S. and Ammann, A.J. (1984) Maternal Transmission of Acquired Immune Deficiency Syndrome. Pediatrics, 73, 382-386. https://doi.org/10.1097/00006254-198410000-00011

[2] Haraud-Bousquet, V., Lot, F., Esvan, M., et al. (2012) A Three Source Capture-Recapture Estimate of the Number of the New HIV Diagnoses in Children in France from 2003-2006 with Multiple Imputation of a Variable of Heterogeneous Catchability. BMC Infectious Diseases, 12, 251. https://doi.org/10.1186/1471-2334-12-251

[3] Townsend, C.L., Cortina-Borja, M., Peckham, M., de Ruiter, A., Lyall, H. and Tookey, P.A. (2008) Low Rates of Mother-to-Child Transmission of HIV Following Ef- 
fective Pregnancy Interventions in the United Kingdom and Ireland 2000-2006. AIDS, 22, 973-981. https://doi.org/10.1097/QAD.0b013e3282f9b67a

[4] Verguet, S., Norheim, O.F., Olson, Z.D., Yamey, G. and Jamison, D.T. (2014) Annual Rates of Decline in Child, Maternal, HIV, and Tuberculosis Mortality across 109 Countries of Low and Middle Income from 1990 to 2013: An Assessment of the Feasibility of Post-2015 Goals. Lancet Global Health, 12, e698-e709.

https://doi.org/10.1016/S2214-109X(14)70316-X

[5] UNICEF (2017) The AIDS Epidemic Continues to Take a Staggering Toll, but Progress Is Possible.https://data.unicef.org/topic/hivaids/global-regional-trends/

[6] Wamalwa, D., Benki-Nugent, S., Langat, A., Tapia, K., Ngugi, E., Slyker, J.A., et al. (2012) Survival Benefit of Early Infant Antiretroviral Therapy Is Compromised When Diagnosis Is Delayed. The Pediatric Infectious Disease Journal, 31, 729-731. https://doi.org/10.1097/INF.0b013e3182587796

[7] Violar, A., Cotton, M.F., Gibb, D.M., Babiker, A.G., Steyn, J., Madhi, S.A., Jean Philippe, P. and McIntyre, J.A. (2008) CHER Study Team: Early Antiretroviral Therapy and Mortality among HIV-Infected Infants. The New England Journal of Medicine, 359, 2233-2244. https://doi.org/10.1056/NEJMoa0800971

[8] Johnson, L.F., Davies, M.-A., Moultrie, H., Sherman, G.G., Bland, R.M., Rehle, T.M., et al. (2012) The Effect of Early Initiation of Antiretroviral Treatment in Infants on Pediatric AIDS Mortality in South Africa: A Model-Based Analysis. The Pediatric Infectious Disease Journal, 31, 474-480.

https://doi.org/10.1097/INF.0b013e3182456ba2

[9] WHO (2010) Antiretroviral Therapy for HIV Infection in Infants and Children: Towards Universal Access. Recommendations for a Public Health Approach. WHO, Geneva.

[10] Chatterjee, A., Tripathi, S., Gass, R., Hamunime, N., Panha, S., Kiyaga, C., et al. (2011) Implementing Services for Early Infant Diagnosis (EID) of HIV: A Comparative Descriptive Analysis of National Programs in Four Countries. BMC Public Health, 11, 553. https://doi.org/10.1186/1471-2458-11-553

[11] Dicko-Traoré, F., Koné, A. and Sylla, M. (2013) Hospitalization’s Reasons of HIV-Infected Children in Gabriel Toure Teaching Hospital, Bamako. Mali Medical, Tome Xxviii $\mathrm{N}^{\circ} 4$.

[12] UNAIDS (2017) Country Factsheets CONGO 2016. http://www.unaids.org/fr/regionscountries/countries/congo/

[13] National Center for Statistics and Economic Studies (CNSEE) Congo and ICF International (2013) Congo Demographic and Health Survey (EDSC-II) 2011-2012. http://www.cnsee.org/pdf/EDSC2012.pdf

[14] Kambourou, J., Moyen, E., Okoko, A.R., et al. (2016) Knowledge and Attitudes of Congolese Women in Prevention of Mother to Child Transmission of HIV. Annals of Health Sciences of Marien NGOUABI University, 16, 2, 7-14.

[15] WHO (2007) Guidance on Provider-Initiated HIV Testing and Counseling in Health Facilities. WHO, Geneva. http://whqlibdoc.who.int/publications/2007/9789241595568_eng.pdf

[16] Ministry of Health, Social Affairs and Family, Republic of Congo (2002) National Policy for the Prevention of Mother-to-Child Transmission of HIV/AIDS.

[17] Ministry of Health, Social Affairs and Family, Republic of Congo (2009) Strategic Framework for HIV/AIDS and STIs in CONGO.

http://www.ilo.org/wcmsp5/groups/public/---ed_protect/---protrav/---ilo_aids/doc uments/legaldocument/wcms_126953.pdf 
[18] WHO (1986) WHO/CDC Case Definition for AIDS. The Weekly Epidemiological Record, 61, 69-76.

[19] WHO (2017) What's New in Treatment Monitoring: Viral Load and CD4 Testing. http://apps.who.int/iris/bitstream/10665/255891/1/WHO-HIV-2017.22-eng.pdf?ua=1

[20] WHO (2006b) Multicentre Growth Reference Study group: WHO Child Growth Standards: Length/Height-for-Age, Weight-for-Age, Weight-for-Length, Weight-for-Height and Body Mass Index-for-Age: Methods and Development. World Health Organization, Geneva.

[21] WHO (2007) WHO Case Definitions of HIV for Surveillance and Revised Clinical Staging and Immunological Classification of HIV-Related Disease in Adults and Children. 11-19. http://www.who.int/hiv/pub/guidelines/hivstaging/en/

[22] Ministry of Planning (2006) Regional Planning and Economic Integration. Congolese Household Survey for Poverty Assessment. http://www.cnsee.org

[23] World Medical Association: Declaration of Helsinki. http://www.wma.net/policies-post/wma-declaration-of-helsinki-ethical-principles-f or-medical-research-involving-human-subjects/

[24] Moyen, G., Mbika-Cardorelle, A., Obengui, et al. (1995) Human Immunodeficiency Virus Infection in the Pediatric Intensive Care Unit of Brazzaville University Teaching Hospital. Revue Internationale de Pédiatrie, 262, 17-21.

[25] Mbika-Cardorelle, A. and Moyen, G. (1998) AIDS in Pediatric Intensive Care. $\mathrm{Me}$ decine d'Afrique Noire, 45, 29-32.

[26] M'pemba Loufoua-Lemay, A.B. and Nzingoula, S. (2003) Aids in CHU (Teaching Hospital) of Brazzaville. Experience Carried out in "Grands Enfants" Pediatric Service. Bulletin De La Societe De Pathologie Exotique, 96, 291-294.

[27] Jones, S.A., Sherman, G.G. and Coovadia, A.H. (2005) Can Clinical Algorithms Deliver an Accurate Diagnosis of HIV in Infancy? Bulletin of the World Health Organization, 83, 559-560.

[28] Van Gend, C.L., Haadsma, M.L., Sauer, P.J.J. and Schoeman, C.J. (2003) Evaluation of the WHO Clinical Case Definition for Pediatric HIV Infection in Bloemfontein, South Africa. Journal of Tropical Pediatrics, 49, 143-147.

https://doi.org/10.1093/tropej/49.3.143

[29] Colebunders, R.I., Greenberg, A., Nguyen-Dinh, P., et al. (1987) Evaluation of a Clinical Case Definition of AIDS in African Children. AIDS, 1, 151-153.

[30] Kankasa, C., Carter, R.J., Briggs, N., Bulterys, M., et al. (2009) Routine Offering of HIV Testing to Hospitalized Pediatric Patients at University Teaching Hospital, Lusaka, Zambia: Acceptability and Feasibility. JAIDS Journal of Acquired Immune Deficiency Syndromes, 51, 202-208. https://doi.org/10.1097/QAI.0b013e31819c173f

[31] Lemos, L.M.D., et al. (2015) Prevalence of and Risk Factors for Late Diagnosis of HIV Infection in Brazilian Infants and Children. Revista da Sociedade Brasileira de Medicina Tropical, 48, 326-330. https://doi.org/10.1590/0037-8682-0257-2014

[32] Kariminia, A., Chokephaibulkit, K. and Pang, J. (2011) Cohort Profile: The TREAT Asia Pediatric HIV Observational Database. International Journal of Epidemiology, 40, 15-24. https://doi.org/10.1093/ije/dyp358

[33] Some, E. and Meda, N. (2014) Does the National Program of Prevention of Mother to Child Transmission of HIV (PMTCT) Reach Its Target in Ouagadougou, Burkina Faso? African Health Sciences, 14, 4.

[34] hIarlaithe, M.O., Grede, N., de Pee, S. and Bloem, M. (2014) Economic and Social Factors Are Some of the Most Common Barriers Preventing Women from Accessing Ma- 
ternal and Newborn Child Health (MNCH) and Prevention of Mother to-Child Transmission (PMTCT) Services: A Literature Review. AIDS and Behavior, 18, S516-S530.

[35] Tejiokem, M.C., Faye, A., Penda, I.C., Guemkam, G., Ateba Ndongo, F., Chewa, G., et al. (2011) Feasibility of Early Infant Diagnosis of HIV in Resource-Limited Settings: The ANRS 12140-PEDIACAM Study in Cameroon. PLoS ONE, 6, e21840. https://doi.org/10.1371/journal.pone.0021840

[36] Sustainable East Africa Research in Community Health (SEARCH) (2016) SEARCH, San Francisco. http://www.searchendaids.com/

[37] Spira, R., Lepage, P., Msellati, P., et al. (1999) Natural History of Human Immunodeficiency Virus Type 1-Infection in Children: A Five-Year Prospective Study in Rwanda. Mother-to-Child HIV-1 Transmission Study Group. Pediatrics, 104, e56. https://doi.org/10.1542/peds.104.5.e56

[38] Obimbo, E.M., Mbori-Ngacha, D.A., Ochieng, J.O., et al. (2004) Predictors of Early Mortality in a Cohort of Human Immunodeficiency Virus Type 1-Infected African Children. The Pediatric Infectious Disease Journal, 23, 536-543. https://doi.org/10.1097/01.inf.0000129692.42964.30

[39] Blanche, S., Newell, M.L., Mayaux, M.J., et al. (1994) Relation of the Course of the HIV Infection in Children to the Severity of the Disease in Their Mothers at Delivery. The New England Journal of Medicine, 330, 308-312. https://doi.org/10.1056/NEJM199402033300502

[40] Becquet, R., Marston, M., Dabis, F., Moulton, L.H., Gray, G., et al. (2012) Children Who Acquire HIV Infection Perinatally Are at Higher Risk of Early Death than Those Acquiring Infection through Breastmilk: A Meta-Analysis. PLoS ONE, 7, e28510.

[41] Diaz, C., Hanson, C., Cooper, E.R., et al. (1998) Disease Progression in a Cohort of Infants with Vertically Acquired HIV Infection Observed from Birth: The Women and Infants Transmission Study (WITS). Journal of Acquired Immune Deficiency Syndromes and Human Retrovirology, 18, 221-228. https://doi.org/10.1097/00042560-199807010-00004

[42] Diarrassouba, G., Adonis-Koffy, L., Niamien, E., et al. (2010) Causes of Hospitalization of HIV Infected Children with in Ivory Coast. Archives de Pédiatrie, 17, 168.

[43] Desmonde, S., Coffie, P., Aka, E., Amani-Bosse, C., Messou, E., Dabis, F., Alioum, A., Ciaranello, A. and Leroy, V. (2011) Severe Morbidity and Mortality in Untreated HIV-Infected Children in a Pediatric Care Programme in Abidjan, Côte d'Ivoire, 2004-2009. BMC Infectious Diseases, 11, 182-182. https://doi.org/10.1186/1471-2334-11-182

[44] Wagner, A., Slyker, J., Langat, A., Inwani, I., et al. (2015) High Mortality in HIV-Infected Children Diagnosed in Hospital Underscores Need for Faster Diagnostic Turnaround Time in Prevention of Mother-to-Child Transmission of HIV (PMTCT) Programs. BMC Pediatrics, 15, 10. https://doi.org/10.1186/s12887-015-0325-8

[45] Chiappini, E., Galli, L., Tovo, P.A., Gabiano, C., Gattinara, G.C., Guarino, A., Badolato, R., Giaquinto, C., Lisi, C. and de Martino, M. (2006) Italian Register for HIV Infection in Children: Virologic, Immunologic, and Clinical Benefits from Early Combined Antiretroviral Therapy in Infants with Perinatal HIV-1 Infection. AIDS, 20, 207-215. https://doi.org/10.1097/01.aids.0000200529.64113.3e

[46] Meyer-Rath, G., Violari, A., Cotton, M., Ndibongo, B., Brenna, A., Long, L., Panchia, R., Coovadia, A., Gibb, D.M. and Rosen, S. (2010) The Cost of Early vs. Deferred Paediatric Antiretroviral Treatment in South Africa-A Comparative Economic Analysis of the First Year of the CHER Trial. 18th International AIDS Conference, Vien- 
na, Abstract No. THLBB103.

[47] Amorissani Folquet, A.M., Daingui, E., Kouadio, E., et al. (2010) Profile of Deaths during Follow-Up for HIV Infection. Archives de Pédiatrie, 17, 170.

[48] Ebissa, G., Deyessa, N. and Biadgilign, S. (2015) Predictors of Early Mortality in a Cohort of HIV-Infected Children Receiving High Active Antiretroviral Treatment in Public Hospitals in Ethiopia. AIDS Care, 27, 723-730.

https://doi.org/10.1080/09540121.2014.997180 